Issues in Information Systems

Volume 18, Issue 2, pp. 71-79, 2017

\title{
PROJECT-BASED LEARNING WITH SYSTEMS ANALYSIS AND DESIGN
}

\author{
Wenli Wang, Robert Morris University, wangw@rmu.edu \\ Paul Kovacs, Robert Morris University, kovacs@rmu.edu \\ Jeanne M. Baugh, Robert Morris University, baugh@rmu.edu
}

\begin{abstract}
Although the IS 2010 Model Curriculum Guidelines for Undergraduate Programs in Information Systems (Topi et al., 2010) highly recommend the use of a course project to facilitate student learning in systems analysis and design, many times there can be a lack of curriculum structural support and heuristics regarding how to facilitate project-based learning in a systems course. Using a course project is important for a systems course because it offers an opportunity for students to practice and integrate both the technical skills and the soft skills learned in the present and the prerequisite courses. These technical-skill competency clusters include data and information management, programming principles and practices, and information technology infrastructure, whereas the soft-skill competency clusters include business analysis, team collaboration, communication, and project management. This paper suggests a curriculum structural support with prerequisite project experiences as well as heuristics concerning how to manage a course project in a systems course.
\end{abstract}

Keywords: Systems Analysis and Design, Project-based Learning, Information Systems Curriculum

\section{INTRODUCTION}

Systems analysis and design (SAD) is one of the seven core courses recommended in the IS 2010 Model Curriculum Guidelines for Undergraduate Programs in Information Systems (Topi et al., 2010) for related degree programs. The IS 2010 Model Curriculum also highly recommends the use of a course project in the SAD course. However, many times there is a lack of curriculum structural support and heuristics regarding how to facilitate project-based learning in a systems course.

Project-based learning has been widely studied by researchers in various disciplines and the results have generally found it to be effective in increasing student motivation, improving student attitudes toward learning, increasing student problem solving and collaboration skills, providing students with an integrated learning situation, addressing different learning styles, and providing growth in self-reliance. Project-based learning increases long-term retention of content, motivates the students to do additional work, illustrates to the students the value of the materials covered, and most importantly, provides practical experiences that enrich the student's academic experiences (Albanese \& Mitchell, 1993; Strobel \& van Barneveld, 2009; Walker \& Leary, 2009; Hanney \& Savin-Baden, 2013; Carter, 2016)

This paper extends the principles and insights in project-based learning in other disciplines to the IS core systems course. Using a course project is important for a systems course because it offers an opportunity for students to learn, practice, and integrate both the technical skills and the soft skills learned in the present and the prerequisite courses. To achieve the objective of students' learning and skill enhancement in multiple facets, it is important to not only manage a course project in a systems course, but also to sufficiently prepare the students in prerequisite course experiences with project assignments for the subsequent core systems course.

The course description for the SAD course in the IS Model Curriculum is as follows:

This course discusses the processes, methods, techniques and tools that organizations use to determine how they should conduct their business, with a particular focus on how computer-based technologies can most effectively contribute to the way business is organized. The course covers a systematic methodology for analyzing a business problem or opportunity, determining what role, if any, computer-based technologies can play in addressing the business need, articulating business requirements for the technology solution, specifying alternative approaches 
to acquiring the technology capabilities needed to address the business requirements, and specifying the requirements for the information systems solution in particular, in-house development, development from thirdparty providers, or purchased commercial-off-the-shelf (COTS) packages. (Topi et al., 2010, p 51)

Therefore, the learning objectives and the required topics to be covered for the systems course are diverse. Students need to be exposed to the theories and practices of systematic methodologies such as the Systems Development Life Cycle (SDLC). They should understand the fundamental topics such as systems theory, the role of the information system in organizations, and systems analysis and design concepts and principles. The purpose, function and expected outcomes of each phase and activity of the SDLC should be discussed from both theoretical and practical perspectives. Specific analysis and design techniques, such as activity diagrams, class diagrams, and data dictionaries, are discussed and used. Other topics include the function of design tools such as Computer-aided Software Engineering (CASE), Gantt chart, project management tools like Microsoft Project.

The mere understanding of these subject areas is not sufficient because students need to apply and integrate these concepts, knowledge, and tools in applications such as a course project to practice experiential learning. Students need to learn both technology and business principles and knowledge and to cultivate relevant skill sets in technology as well as the management of a course project.

This paper describes the curriculum structural support for a course project in a systems course and the heuristics of managing such a course project. This project-based approach can be useful for integrating a number of essential knowledge, skills, and competencies learned in an Information Systems program of study and for preparing the students well for future internships and jobs in organizations.

\section{PREREQUISITE PROJECT EXPERIENCES}

The IS Model Curriculum has extensively mapped out the core and elective courses with the suggested course sequences in the related undergraduate IS degree programs. However, it only suggests the use of a group project, a course project, or an integrated project in the discussions of the core and elective courses without further discussing how these projects are related or built upon each other in the curriculum. This study fills in such a gap and recommend prerequisite project experiences for a course project in a core systems course.

Although the IS Model Curriculum has provided a course map for IS 2010 core courses (Topi et al., 2010), it provides only general guidelines on the sequencing of the core courses. The core course of "Foundations of IS" presides the five core courses of "Data and Information Management," "Enterprise Architecture," "IS Project Management," "IT Infrastructure," and "Systems Analysis and Design," and these five courses are followed by "IS Strategy, Management, and Acquisition." Such general guidelines do not specify what the sequence is between project management and SAD. This general approach leaves much flexibility to related undergraduate IS degree programs to arrange the courses in a sequence that fits a particular degree programs' needs. However, this flexibility also provides a challenge for an instructor in a SAD course in that the instructor cannot assume a student has prior exposure to projects and the concepts of project management.

Another challenge is that a course project is highly recommended for a systems course. However, the concepts of project management cannot be assumed to have been provided to the students and during a systems course even though project management is one of the main topics to be covered extensively. In the IS 2010 Model Curriculum (Topi et al., 2010), topics to be covered in a SAD course related to projects are: "structuring of IT-based opportunities into projects," "project specification," "project prioritization," "analysis of project feasibility," and "fundamentals of IS project management in the global context." This challenge causes a "chicken and egg" problem regarding when and how to offer a course project to the students. And this problem escalates when a systems course is offered not in a traditional fifteen-week format but in an eight-week or a ten-week format.

Often times in IS degree programs the required prerequisites for a systems course only provide the students with the necessary building blocks of technical knowledge and skills. There is no requirement as to the prior exposures to or experiences of projects and project management, which also train the students in soft skills. 


\section{Issues in Information Systems}

Volume 18, Issue 2, pp. 71-79, 2017

If a course project is adopted by an instructor in a systems course but students have not yet been exposed to projects or project management in the prerequisite courses (which implies that the extensive concepts of project management are introduced only during the systems course), students may feel overwhelmed and do not know where to start with a course project. Therefore, in order to lead up to a course project, the student should have had several prerequisite courses where projects have been assigned and the concepts of project management are at least demonstrated by the instructor(s).

It is recommended that the prerequisite courses include projects and some exposure of project management. These projects can be mini or course projects, individual or group projects. The exposures of project management can be in the informal introduction to the concepts or the demonstration/role modeling by the instructor.

For instance, if a programming course is a prerequisite course for SAD, a large programming project can be assigned after the students have written a few small programs that practice some of their basic programming skills. Such a large programming project can even be a semester long course project. Students can create stubs within their code, and add code throughout the rest of the semester as new programming skills are acquired. Figure 1 indicates the basic progression of the programming topics in such a course which eventually leads to a large programming effort.

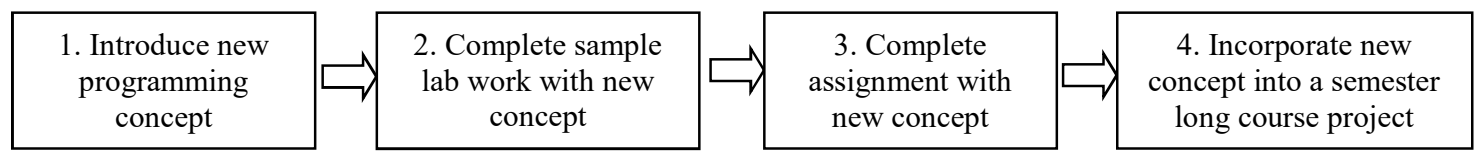

Figure 1. Sequence of new programming concept introduction to students

The large programming project should be broken into phases. Sample assignments for Phase I and II are as follows:

In Phase I of the semester project, you will be creating the entire structure of the program. You will have a menu that will call the proper method depending on the user selection. When the method is called, the only thing that will execute is a System.out statement telling the user that the proper code has executed. All of the code for each method will be added during later phases of the program. You will be creating a program that calls stubs. A stub is a piece of code that is executed, but really has no functionality. It is simply a place holder for where code eventually will be placed.

Phase II of the project involves keeping track of information that is sorted in parallel arrays. In this phase, you will read in member, class and registration information. There is a program in the web site that shows how to read data from a text file. This program is called file_info.java. Please download it and follow how it is set up for reading in a text file. You will define each array to be at most 100 elements big. But you will have to keep track of how many of each array elements that have actually been stored. Therefore, you will need three count variables, to keep track of the number of members, classes and registration that have been read in. Because your program uses methods, all arrays and the counts will have to be passed to the methods that need them. In the third phase of the project, you will be changing the program to use a class and the data will no longer have to be passed. But for now, you just have one class with the methods within it. If you have experience with classes, you are not to use them in Phase II.

The course project in a programming course can be selected for the students by the instructor and the instructor can strictly enforce the time constraints (Baugh \& Kovacs, 2014). Since programming is essential for a technical course project in a systems course, a prerequisite programming project would have provided the students with a solid basis of understanding the logical behavior of the computer (Baugh \& Kovacs, 2014) and the IT components in an IT architecture, as well as exposure to project and project management.

Similarly, a "Data and Information Management" core course such as Database Management could also be the prerequisite course for the systems course and it should also include a semester project. In an example course taught by the authors, students are required to select a project of their own choosing (with the advice of the instructor). The students are required to do an in-depth analysis of the user's data requirements. In most of the cases, the students are working with actual clients/users and will implement the user's view of their enterprise or organization. Students spend a great deal of time on data design, which is essential in many systems project. Students then create the database 


\section{Issues in Information Systems}

Volume 18, Issue 2, pp. 71-79, 2017

according to the data design specifications. They are also required to complete the associated documentations, a User's Guide and a Technical Programmer's Guide. Because the students select their own projects, they are much more interested in the completion of their projects (Baugh, 2013). Their experiences in a data management project prepare them for a larger-scale systems project or a follow-up advanced database course (Seyed-Abbassi, 2002).

A sample of the initial database project assignment is as follows:

You are required to complete an individual database project. Your database can be about anything you like. You are to create an initial Entity Relationship diagram for your database project. On this diagram, you are to include the following:

- All entities sets

- All relationships (give a name for each)

- All carnalities of the relationships

- Define a key for each entity set (place it on the diagram)

In addition to the entity relationship diagram, you are to explain in detail what your database is about. You need to explain what you are doing, why you are creating the database (what it will be able to do) and how you are going to do it (the ER diagram)

Your explanation needs to also include the following:

- A detailed explanation of each entity set

- A detailed explanation of the relationships among the entity sets

- A list of various queries that could be run from the database

A traditional project management course would give the students many tools that could be used in conjunction with any project for any other course. Among many other topics, students are exposed to time and resource management. A project could be assigned over the entire semester. All phases of the project would be explored, from defining the scope at the onset, to lessons learned at its completion. In this course, software, such as Microsoft Project and various Excel templates could also be used. Since a project is something considered to have a finalized state, the skills students acquire in a project management course would transfer quite well to other courses offered in an Information Systems curriculum.

A sample of a project management assignment is as follows:

Substitute employees in the school district of California PA are hired based on their qualifications. They are then assigned jobs through a rotating schedule based on their "turn" in the list. For example, a person may be first on the list to be called when a sub is needed. If that person turns down the job for the day, the next person on the list will be called and the original person called will move to the end of the list. This process is used for all subs from teachers to maintenance workers. The Superintendent of the California School District, Dr. James Gallo has become increasingly concerned that the process for calling in subs is not being followed. You have been hired as an outside IT consultant and have been tasked with creating a "computer solution" to the problem. The solution must be up and running in 3 months. For this project, you may make any assumptions you like and are to create the following:

- Create a Scope statement. In the scope statement, you must define the deliverables, including the schedule, budget and product/service. You must define all stakeholders

- According to the scope statement you have defined in step \#1 above, define the WBS

- Define all Resources that are needed for the project (include WORK and COST Resources)

- Create a network diagram using the WBS from step \#2 above

- Using the Stakeholders defined in step \#1 above, create a Responsibility Matrix (RACI or RASIC)

No matter what prerequisite courses are chosen in undergraduate IS degree programs, these prerequisites often focus on the technical skills competency clusters of data and information management, programming principles and practices, and information technology infrastructure. However, students also need to be exposed to the soft skills competency clusters of business analysis, team collaboration, communication, and project management, and these soft 


\section{Issues in Information Systems}

Volume 18, Issue 2, pp. 71-79, 2017

skills are also needed for the project-based systems course. Even if there are no specific prerequisite courses for cultivating these soft skills, the instructors in the technical prerequisite courses could at least demonstrate these soft skills. For instance, in a programming course with a large programming project, the instructor can prescribe the time management of the project workload. Therefore the students are forced into allocating the necessary time to complete each phase of the project. This teaches and exemplifies the students to be very organized in their approach to the completion of a semester project, which is essential to a course project in the subsequent systems course.

\section{PROJECT-BASED LEARNING IN A SYSTEMS COURSE}

As mentioned earlier, it is a challenge to manage a project in a systems course where project management is one topic to be covered in the middle of the course itself and a highly recommended project by the IS Model Curriculum is not a mini-project but a semester-long course project. Besides the curriculum structural support with the prerequisite project experiences, strategies and heuristics are needed to face such a challenge in order to manage the course project and facilitate the project-based learning from the students. The heuristics are discussed in the three stages or steps of the course project: project initiation, project development, and project evaluation.

\section{Project Initiation Stage}

\section{Project Selection}

If a project is a mini project, the project selection time is not as crucial as that for a semester-long project. But for a semester long course project, effective project selection is critical to the success of the project and should be accomplished during the first or the second class meetings of the course.

A project can involve either a simulated or a real-world application. In a simulated project, the instructor creates a scenario or uses a textbook case and acts as the client and/or end-user. A simulated project allows for control over the requirements by the instructor, and most importantly, incomplete projects during the course duration are not an issue. Examples of simulated projects used by the authors in a SAD course include a fictitious online store selling clothing and a pizza restaurant which accepts online orders.

As effective as an instructor may be, a simulated project in a classroom setting does not offer students the benefits that can be gained by working with a real-world project. The requirements with a real-world project can originate with an actual client and/or end-user in a community. With a real-world project, the instructor does not have the complete control because the requirements come from an actual client/end-user. As a result, the time commitment from the instructor can be much greater due to answering student questions about real-world scenarios as well communication with the client/end-user. Faculty not only have to manage the project but they also have to fulfill campus commitments when dealing with real-world projects.

An additional challenge of using a real-world project involves the stability of the projects once the course has ended. Changes may occur within the project that demand the systems to be updated. This residual challenge should be considered before the commitment of introducing students a real-world project and working with an actual client/enduser.

Peterson et al., (2006) express that these limitations can be overcome by careful planning and that clients/end-users need to be aware of university policies regarding procedures and particular attention must be given to scope and time management issues because the students have only a semester to complete the system. As a result, the authors have created a document for both the learning institution and the actual client/end-user to sign that clarifies the roles of the involved parties and the limitations and constraints involved.

A case in point involved one of the author's experiences in developing a system for a local auto parts store, in which end-users could search for and order parts. The project had no more than six components and involved five teams with seven students in each team. The time constraints were met at every critical point. Another project consisted of a career posting website for a local entrepreneur that allowed job candidates and companies seeking employees to post 


\section{Issues in Information Systems}

Volume 18, Issue 2, pp. 71-79, 2017

their profiles and new job opportunities respectively. Given the level of student expertise and the scope of the project, it was impractical to implement all of the requirements in the allotted time frame and was not completed at the end of the semester. As a result, the project had to be finished the following semester by students in the directed study format.

\section{Team Selection}

Due to the typical complexity of a course project, a systems course project is mostly a team project unless a student volunteers to take it on individually. It has shown that a team project has a higher project completion rate and better project performance than those of an individual project (Wang, 2015b). Project teams should be formed as early as possible to allow time for team-building before the real work of the project begins. It is recommended to form the team within the first two class meetings for a semester-long fifteen-week systems course. If the course lasts only eight or ten weeks, then the project team should be formed in the first class meeting.

The successful establishment of a team requires that the team be of appropriate size and based on the individual skill set of each team member. The size of the team is influenced by the class size as well as the number of project components of the system. It is not necessarily the bigger the team size, the better the team performance. It has shown that with the same project in the same systems course taught by the same instructor across different semesters, teams with a size of two have a higher project completion rate and better project performance than those with a larger team size such as four (Wang, 2015b).

Roles and responsibilities define the functions performed by members of the team. To determine the specific role of team members, students are asked to indicate to the instructor what courses they have completed in Technology and in Business as well as their individual systems experiences and preferences. Some students may be more competent or interested in one functional role or area as opposed to another. For example, a student may have much exposure to Business and prefer leading the business analysis of the project. Another example is that a student may have taken a multimedia graphics course and hence be interested in designing human-computer interfaces as opposed to programming the databases.

To aid the instructor in selecting roles for teams, a proficiency/preference questionnaire can be constructed by the instructor and distributed to the class. The instructor can also ask the students to present their background, experiences, and preferences in front of the class so that students can self-select their team members. The assignment to each team is then based on the students' self-selections in combination with the instructor's recommendation or even team assignment based on the results of the proficiency/preference list. It should be noted that a students with a high level of competency in one area can be paired with a student not proficient in that area. This can be a great learning experience for both students.

\section{Project Management}

Since no project management content has been formally covered in the systems course during the first one or two class meetings, the instructor needs to initiate the project management for the teams. Take an example for the time management: the instructor needs to decide on the overall time management requirement and each team must respond to this requirement and decide on its own time management strategies early on in the project.

\section{Project Development Stage}

Even after the initial setup of project-related activities such as project selection, team selection, and project management initiation at the beginning of the systems course, these activities still need to be managed and monitored during the project development throughout the course.

For instance, students may withdraw from the course and other students may enroll. Even if the number of students withdrawn or newly-enrolled is small, it still affects the team and team members may need to be shifted. In addition, in the middle of the course, some team members may have conflicts with each other and these conflicts, in the worst scenarios, may require the change of the teams. 


\section{Issues in Information Systems}

Volume 18, Issue 2, pp. 71-79, 2017

Similarly, the students' initially-selected roles may change during the development of the course. A student who is competent on the technical side may later decide to challenge themselves with more business related endeavors and choose a different role. The instructor may even suggest the change to a student after further observing and examining the students' capabilities and capacities. Both the selected project and the team can be fluid, especially in the first month of the project.

Project management or time management is also necessary during the entire cycle of the project development. The authors have employed two approaches when dealing with time management. One approach was to have the instructor act as a project leader and require the teams to submit a specific component of the project by a specific date in the semester. The other approach was to allow the team members complete control and have them select a project leader and manage their own time with a final due date. The first approach gives the instructor more control and the second approach gives the team members the responsibility for completion of the project. The authors' experience with using both approaches was that the first approach had more positive results when completing a project. Each team is required to report its time management strategies such as when, how often, and via which medium (virtual or face-to-face) the team would meet and what the remedial actions would be if a team member does not complete assigned work on time.

Related to the time management is the identification and enforcement of benchmark deliverables. Depending upon the complexity of the project, the number of deliverables and the time for the deliverables can vary. These deliverables are even more difficult to control for a real-world project due to the increased complexity and the involvement of external parties. Nevertheless, each team is required to provide deliverables to the instructor and to mark progress within the team. There may not be hard deadlines consistent for all teams, but the instructor still needs to enforce general deliverable requirements and deadlines with some built-in flexibilities.

Since it is also important for students to build and practice the soft-skill competency clusters of business analysis, team collaboration, communications, and project management, after the instructor initiates and recommends the strategies to build these skills for the students, students should later take the further initiatives and full responsibilities themselves, especially during and after the teachings of the related project management content. The instructor then reinforces multiple times throughout the course regarding the good practices of project management.

\section{Project Evaluation Stage}

In education, it is important to evaluate students' performance and provide constructive feedback to the students. Project and student evaluation is hence an integral element in teaching a project-based systems course. It is recommended to evaluate projects and students in three basic ways: benchmark deliverables, complete project, and individual's contributions to the team. The benchmark deliverables and the completed project are the basis for project evaluation, and the individual's contribution to the team is the basis for additional student evaluation. All three basis contributes to the student final course grade.

Benchmark deliverables: Depending upon the complexity of the application, the number of deliverables can vary as well as the points for each. A rubric or checklist can be constructed to keep track of theses deliverables so the students are aware of the progress they are making. Depending upon what percentages are used in the grading criterion for the completed project, this requirement can consist of 20 to 30 percent of the final grade.

Completed project: the completed project accounts for the largest percentage of the final grade, in the range of 40 to 60 percent. The project grade is divided into several components. The deliverables the instructor has collected during the weekly meeting comprises one component, while another component is the degree of completion of the project, based upon the overall requirements.

Individual contributions to the team: Each student's individual contribution to the team is the basis for individual student's evaluation for the project. Many times, some members of a team do most of the work and others do not. So rather than the instructor making this determination solely through his/her observation, it is recommended to have individual team members evaluate each other as per an anonymous evaluation sheet constructed by the instructor. 


\section{Issues in Information Systems}

Volume 18, Issue 2, pp. 71-79, 2017

For example, Wang (2015a) provided the detailed background information of an exemplary systems course project that asks the students to conduct the web design for a non-profit contemplation-related organization and its subsidiaries. The students were split into groups with each group conducting the systems analysis and design for either the main organizational website or one of its subsidiaries. Wang $(2015 \mathrm{~b})$ provided a sample project proposal template that serves both as a guidance to the students and a starting rubrics for grading benchmark deliverables and completed project. The students were asked to work on different sections of the template along with the progress of the course and then to integrate and present the complete project at the end of the semester. An excel spreadsheet was developed to evaluate the final project presentation by both the instructor and the students. However, the instructor's evaluation carries the most weights (e.g., contribute $90 \%$ ) in the final project's grading as the students tend not to have reliable evaluation standards and are inexperienced in grading.

In summary, not only do students need to receive lectures in systems methodologies such as the systems development life cycle and related technical and business content in a systems course, the instructor also needs to provide opportunities for the students to practice learned systems knowledge and skills in the same course. A project-based systems course has more challenges and requires more organization for the instructor. The above mentioned heuristics in the three stages of project initiation, project development, and project evaluation can serve as a blue print for promoting project-based learning.

\section{CONCLUSIONS}

One main purpose of a project-based systems analysis and design course is to allow Information Systems students to integrate and apply essential knowledge and skills learned in an Information Systems program of study. Although the IS 2010 Model Curriculum and Guidelines for Undergraduate Programs in Information Systems (Topi et al., 2010) highly recommends the use of a course project to facilitate student learning in systems analysis and design, there is a lack of curriculum structural support and heuristics regarding how to promote project-based learning in a systems course. This paper recommends prerequisite project experiences and provides heuristics in managing the course project in three stages: project initiation, development and evaluation.

This project-based curriculum design and practice leading to and managing of a successful systems course involves more than just traditional classroom instruction on the theories and frameworks of systems science and on the systems course alone. It involves prerequisite course and experiences to prepare the building blocks of skills sets and competencies. It also involves strategies that enable and support students to work in a team environment and apply not only their technical skills but also develop their soft skills such as business analysis, team collaboration, communication, and project management. The opportunity to participate in a systems project from the initiation through implementation is an excellent way to prepare the students and increase their confidence when embarking on a career.

Such a project-based approach in a systems course is never complete, and semester-by-semester revision is necessary. This approach can also be quite time consuming for both the instructor and the students, but the positive rewards are evident by feedback from students who have completed a project. Almost without exception, every student expressed an appreciation for the learning experience and some students even obtained internships as systems analysts during or soon after the systems course.

\section{REFERENCES}

Albanese, M., \& Mitchell, S. (1993). Problem-based learning: a review of literature on its outcomes and implementation issues, Academic Medicine, 68(1), 52-81.

Baugh, J. M. (2013). Real world design and implementation in the student's first database course, Issues in Information Systems, 14(1), 441-450.

Baugh, J. M., \& Kovacs, P. J. (2014). Programming not required? Did the IS-model curriculum get it right? Issues in Information Systems, 14(1), 399-408. 


\section{Issues in Information Systems}

Volume 18, Issue 2, pp. 71-79, 2017

Carter, S. (2016). Traditional vs. Project-based learning: The effects on student performance and motivation in honors level mathematics courses ((Doctoral dissertation). Retrieved from http://digitalcommons.liberty.edu/cgi/viewcontent.cgi?article=2309\&context=doctoral.

Hanney, R. \& Savin-Baden, M. (2013). The problem of projects: understanding the theoretical underpinnings of project-led PBL. London Review of Education, 11(1), 7-19.

Peterson, B., Yockey, J., Larsen, P., Twidwell, D., \& Jorgensen, K. (2006). Service-learning projects: meeting community needs, Home Health Care Management \& Practice, 18(4), 315-322.

Schulmeyer, G., McManus, J. I. (1999). Guide to Software Quality Assurance, New Jersey: Prentice Hall PTR.

Seyed-Abbassi, B. (2002). The evolution of an advanced database course in an information systems curriculum, Proceedings of the 19th Annual Conference on Information Systems Education.

Strobel, J., \& van Barneveld, A. (2009). When is PBL more effective? A meta-synthesis of meta-analyses comparing PBL to conventional classrooms. The Interdisciplinary Journal of Problem-Based Learning, $3(1)$.

Topi, H., Valacich, J. S., Wright, R. T., Kaiser, K., Nunamaker, Jr., J. F., Sipior, J. C., de Vreede, G. J (2010). IS 2010: curriculum guidelines for undergraduate degree programs in information systems. Retrieved from https://www.acm.org/education/curricula/IS\%202010\%20ACM\%20final.pdf

Walker, A. \& Leary, H. (2009). A problem-based learning meta analysis: Differences across problem types, implementation types, disciplines, and assessment levels. Interdisciplinary Journal of Problem-based Learning, 3(1), 12-43.

Wang, W. (2015a). Building a contemplative IS workforce through promoting mindfulness in IS design, Proceedings of the 18th Americas Conference on Information Systems (AMCIS). San Juan, Puerto Rico.

Wang, W. (2015b). Lessons learned from teaching project-based systems analysis and design, Issues in Information Systems, 16(4), 132-142. 